\title{
Formation of Calcium Carbonate Polymorphs Induced by Living Microalgae
}

\author{
Giulia Santomauro*, Johannes Baier, Wanjing Huang, Stefan Pezold, Joachim Bill
}

Institute for Materials Science, University of Stuttgart, Stuttgart, Germany.

Email: *giulia.santomauro@imw.uni-stuttgart.de

Received August $7^{\text {th }}, 2012$; revised September $17^{\text {th }}, 2012$; accepted September $26^{\text {th }}, 2012$

\begin{abstract}
Calcium carbonate $\left(\mathrm{CaCO}_{3}\right)$ occurs in the three polymorphs calcite, aragonite and vaterite. The formation of these crystals in inorganic solutions is influenced by parameters like $\mathrm{pH}$, temperature or impurities. Living freshwater microalgae can also induce the formation of $\mathrm{CaCO}_{3}$ when they live in a suitable environment containing saturated amounts of $\mathrm{Ca}^{2+}$. Through this biologically induced biomineralization only the formation of the polymorph calcite has been reported yet. We investigated the precipitates which have been formed in solutions containing the freshwater microalgae Scenedesmus obliquus and different zinc amounts $\left(0,3.27\right.$ and $\left.6.53 \mathrm{mg} \mathrm{Zn}^{2+} / 1\right)$ by XRD and SEM. As references precipitates from the same solutions but without algae were investigated. We could show that the presence of living microalgae has a great influence on the precipitation of calcium carbonate crystals. In algae-containing media without or with a low zinc amount always calcite and aragonite are formed. In the corresponding medium with $6.53 \mathrm{mg} \mathrm{Zn}{ }^{2+} / 1$ pure aragonite crystals were built. In contrast, in the inorganic, algae-free solutions without zinc, pure calcite is precipitated. Both inorganic solutions with zinc show major calcite precipitation and weak aragonite precipitation. Thus the algae cells advance significantly the formation of aragonite, which is enhanced by the presence of zinc cations in the media. Possible mechanisms are discussed.
\end{abstract}

Keywords: $\mathrm{CaCO}_{3}$ Polymorphs; Biomineralization; Zinc; Microalgae; XRD

\section{Introduction}

The formation of the three calcium carbonate $\left(\mathrm{CaCO}_{3}\right)$ polymorphs calcite, aragonite and vaterite in inorganic solutions has been the topic of many studies [1-4]. It was proposed that first an unstable amorphous phase is built which transforms to the metastable phase vaterite or aragonite, followed by the transformation to the stable phase calcite [1]. The precipitation of the polymorphs can be affected by different factors like temperature, $\mathrm{pH}$ of the medium, concentration ratio of individual components, supersaturation, ionic strength or impurities [3]. The investigations of Ogino et al. (1987) [1] revealed that aragonite formation is favored at higher temperatures $\left(>40^{\circ} \mathrm{C}\right)$ in aqueous solution, which has also been supported in other experiments [4]. At room temperature, the $\mathrm{pH}$ of the solution in a constant-composition environment is the most important factor for the formation of the polymorphs [3]. At $24^{\circ} \mathrm{C}$, vaterite is the major product in the $\mathrm{pH}$ range between 8.5 and 10. Aragonite preferably formed at $\mathrm{pH} 11$; when the $\mathrm{pH}$ is higher than 12 , calcite is the dominant product. The precipitation of the different polymorphs can also be modified by impurities in the

${ }^{*}$ Corresponding author. solution. When the ionic radius of the impurities is smaller than that of the $\mathrm{Ca}^{2+}$ cations, what is the case for $\mathrm{Zn}^{2+}$ cations [5], aragonite is deposited [6]. This influence is explained by adsorption phenomena on the crystalline faces of the nuclei. Kitano et al. (1976) [7] examined specifically the adsorption behavior of $\mathrm{Zn}^{2+}$ on $\mathrm{CaCO}_{3}$ polymorphs in aqueous solutions. They showed that $\mathrm{Zn}^{2+}$ is strongly adsorbed on aragonite crystals in comparison to other polymorphs. It was assumed that the zinc ions inhibit the transformation of aragonite to calcite $[1,7]$. The $\mathrm{Zn}^{2+}$ adsorption on the calcite surface occurs via an exchange of $\mathrm{Ca}^{2+}$ in a surface-adsorbed layer [8].

Also organic additives show an effect on the mineralization of calcium carbonate (reviews in: Meldrum, 2003 [9]; Ren et al., 2011 [10]). Amino acids like glycine, aspartic acid and glutamic acid or polysaccharides like cellulose influence the precipitation and morphology of calcite and vaterite [11-13].

Living organisms like photosynthetic microalgae can induce the precipitation of $\mathrm{CaCO}_{3}$ through biomineralization. It is known that many freshwater algae build calcite crystals when they live in a supersaturated environment regarding calcium $[14,15]$. This is a result of the 
influence of the algae's metabolism on their aqueous environment [16]. Through photosynthesis the algae assimilate $\mathrm{CO}_{2}$ and/or $\mathrm{HCO}_{3}^{-}$, and release $\mathrm{OH}-[16,17]$. This leads to an increase of the $\mathrm{pH}$ and the concentration of carbonate anions within the solution. It is also largely accepted that the $\mathrm{pH}$ affects both number of cell surface binding sites and metal chemistry within aqueous solution: in the acidic range, the functional groups of the cell wall are closely protonated, which limits the approach of metal cations. The cell walls of green algae consist of polysaccharides and proteins $[18,19]$. With increasing $\mathrm{pH}$, more functional groups, such as carboxyl or amino groups, are exposed, which increases the biosorption of metal ions on the negatively charged cell walls. In the first step, $\mathrm{Ca}^{2+}$ is bound on the cell wall, and afterwards $\mathrm{CO}_{3}^{2-}$ anions are accumulated and $\mathrm{CaCO}_{3}$ is precipitated extracellular. This mechanism is named biologically induced [16], because the calcification is not actively controlled by the organisms. In the biologically controlled biomineralization, different types of biominerals are produced under the genetic control of the organisms. Up to now, in the presence of freshwater microalgae only the extracellular biologically induced formation of calcite is reported.

Positively charged metal ions can also be bound on the cell surfaces of living organisms [e.g. 20-27]. Zinc is an essential trace metal for all organisms, but can be toxic when present in high amounts. Exposure of microalgae to sublethal $\mathrm{Zn}^{2+}$ concentrations caused inhibition of e.g. photosynthesis [28]. When the algae are confronted to toxic elements like $\mathrm{Zn}^{2+}$ in their environment, they detoxify it by taking up the ions. The uptake is split in two steps: the first is a rapid biosorption onto the cell wall, during the second step the ions are transported into the cells [29]. Subsequently, the interior of the cells can be detoxified by chelating the $\mathrm{Zn}^{2+}$ cations to e.g. nontoxic zinc-phosphate-based nano needles [30].

The aim of this study was to investigate the role of living algae on the precipitation of different polymorphs of calcium carbonate. For the experiments the unicellular alga species Scenedesmus obliquus (Chlorophyta) was cultivated in media with and without $\mathrm{Zn}^{2+}$ and the results were compared to the inorganic media without algae. This alga species was chosen because preliminary experiments have shown that it calcifies readily when cultured in supersaturated media regarding $\mathrm{Ca}^{2+}$.

\section{Materials and Methods}

\subsection{Organisms and Cultures}

The experiments were conducted with living Scenedesmus obliquus (strain 276-1), obtained from the SAG culture collection Göttingen. The algae were cultivated in a modified calcification medium [17], where $\mathrm{Na}_{2}$ EDTA,
$\mathrm{KH}_{2} \mathrm{PO}_{4}$, $\left(\mathrm{NH}_{4}\right) \mathrm{Mo}_{7} \mathrm{O}_{24}$ and $\mathrm{MnCl}_{2}$ were omitted and $\mathrm{FeCl}_{3}$ was reduced to $0.01 \mathrm{mg} / \mathrm{l}$ to prevent chelate formation with $\mathrm{Zn}^{2+}$. The solution was saturated regarding $\mathrm{Ca}^{2+}$. The media contained different amounts of zinc $(0 \mathrm{mg}$ $\mathrm{Zn}^{2+} / 1,3.27 \mathrm{mg} \mathrm{Zn}{ }^{2+} / 1$ or $\left.6.53 \mathrm{mg} \mathrm{Zn}{ }^{2+} / 1\right)$, added as $\mathrm{ZnSO}_{4} \cdot 7 \mathrm{H}_{2} \mathrm{O}$ (Roth, Karlsruhe). Preparation of the media: all stock solutions beside $\mathrm{Na}_{2} \mathrm{CO}_{3}$ were sterilized (autoclave Systec V-75) and combined, the $\mathrm{pH}$ was adjusted to 6.3. The algae were washed in demineralized water (Millipore), counted with a hemocytometer ( $\mathrm{Ma}$ rienfeld, Lauda-Königshofen) to ensure the same cell concentration in all cultures and added to the medium (about $4.0 \times 10^{8}$ cells/l). The culture was held in a rotary shaker (Infors HT Multitron II, $100 \mathrm{rpm}$ ) at $26^{\circ} \mathrm{C}$ and permanent illumination (FL tubes Gro-Lux 15W, 3500 lx). Due to photosynthesis, the $\mathrm{pH}$ increased to a value over 9 during several days. Not till then the $\mathrm{Na}_{2} \mathrm{CO}_{3}$ was added to prevent loss of $\mathrm{CO}_{3}^{2-}$ anions and the $\mathrm{pH}$ was adjusted to 8.5. At this point the experiment started. The inorganic, algae-free solution was prepared identically; the $\mathrm{pH}$ was adjusted daily according to the organic, algae-containing solution with $0.1 \mathrm{M} \mathrm{NaOH}$. The duration of the experiment was $72 \mathrm{~h}$. After this time all cultures were living as revealed by their green color.

\subsection{SEM Measurement}

Precipitation of crystals was investigated after 2, 4, 6, 24 and $72 \mathrm{~h}$ duration of the experiment. For observation in a scanning electron microscope (Zeiss DSM 982 GEMINI) the specimens were washed in demineralized water (Millipore) using a glass vacuum filter system with $0.2 \mu \mathrm{m} / 2$ $\mu \mathrm{m}$ pore size filter membrane (Millipore) and then air-dried. To obtain electron conductivity, the membranes were coated with graphite.

\subsection{Powder X-Ray Diffractiometry (XRD)}

XRD was used to identify the $\mathrm{CaCO}_{3}$ polymorphs after $72 \mathrm{~h}$ duration of the experiment. The XRD patterns were recorded with a D500 diffractometer (Siemens). Measurements were made in Bragg-Brentano geometry, using $\mathrm{CuK} \alpha_{1}$ radiation (X-ray tubes setting of $30 \mathrm{~mA}$ and 40 $\mathrm{kV}$ ) employing a primary-beam Johansson monochromator in a $2 \Theta$ range of $20^{\circ}$ to $50^{\circ}$.

\section{Results \& Discussion}

\section{1. pH Trend}

At the beginning of all experiments the $\mathrm{pH}$ of each culture was adjusted to 8.5. Due to photosynthesis of the algae, the $\mathrm{pH}$ rose up to 10.8 after $48 \mathrm{~h}$ in the culture without zinc; afterwards it stayed nearly constant (Figure 1). In presence of zinc, the $\mathrm{pH}$-shift was retarded and did not reach the high values of the culture without zinc. This 
is due to the fact, that $\mathrm{Zn}^{2+}$ cations restrain photosynthesis of algae. The $\mathrm{pH}$-shift is correlated to $\mathrm{Zn}^{2+}$ concentration within the solution: the culture with $6.53 \mathrm{mg} \mathrm{Zn^{2+ }} / 1$ only reached $\mathrm{pH} 10.1$ after $72 \mathrm{~h}$, the culture with $3.27 \mathrm{mg}$ $\mathrm{Zn}^{2+} / 1$ reached $\mathrm{pH} 10.5$ after $48 \mathrm{~h}$ and remained at this value. According to the observed $\mathrm{pH}$ values in cultures containing algae, the $\mathrm{pH}$ in the media without algae were adjusted daily with a $0.1 \mathrm{M} \mathrm{NaOH}$ solution.

\subsection{Precipitation of Crystals and Identification of Polymorphs}

The formation of precipitates was investigated at the starting point of the experiments and after $2 \mathrm{~h}, 4 \mathrm{~h}, 6 \mathrm{~h}$, $24 \mathrm{~h}$ and $72 \mathrm{~h}$ in solutions with algae.

At the starting point of the experiments, there was no precipitation on the algae (Figure 2(a)). After $2 \mathrm{~h}$ of incubation, crystals with embedded algae could be detected in the cultures without zinc (Figure 2(b)). In the next hours the crystals grew bigger (data not shown). In the cultures with zinc, no crystallization occurred during the first $6 \mathrm{~h}$ (data not shown).

After $24 \mathrm{~h}$ of incubation, in all solutions precipitates could be found (data not shown). In the media with algae and with zinc, big crystals occurred with diameters of about $50 \mu \mathrm{m}$. Always many algae were embedded in these crystals. In the inorganic solutions with $\mathrm{Zn}^{2+}$, only very small precipitates were found $(\varnothing$ below $100 \mathrm{~nm}$; REM image, data not shown).

After $72 \mathrm{~h}$ of incubation, in all solutions crystals were found which differed greatly in their dimensions and morphology (Figure 3). The precipitates formed in the organic solutions contained several (Figures 3(a) and (c)) or many algal cells (Figure 3(b)). The largest precipitate, where always many algal cells were incorporated, were

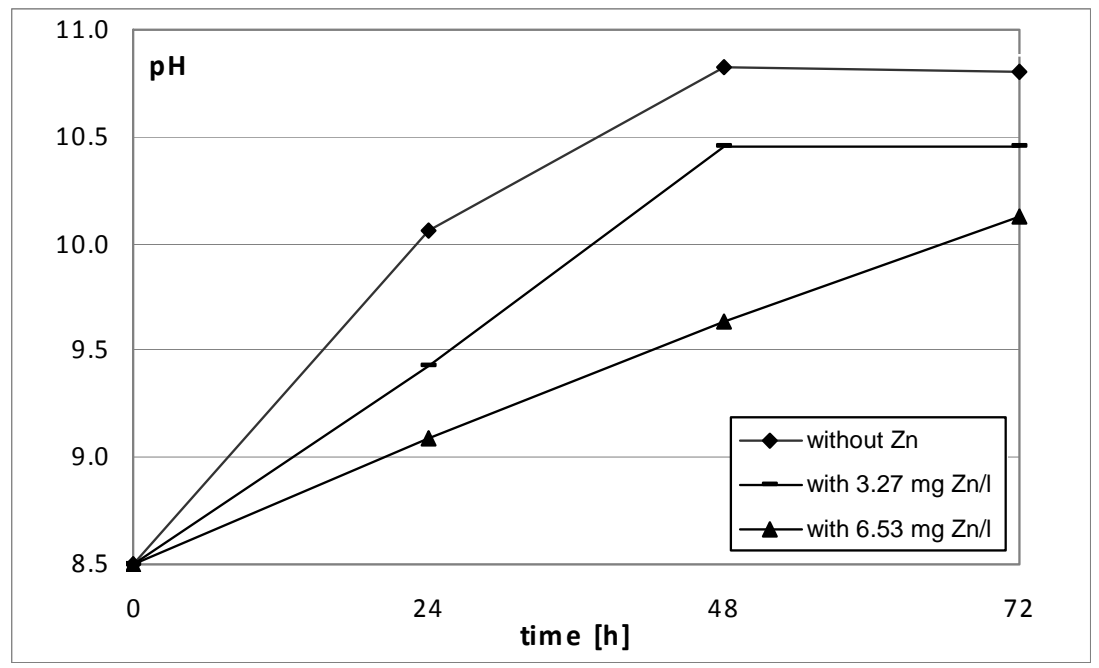

Figure 1. pH shift in the cultures with algae and different zinc amounts during the experimental time of $72 \mathrm{~h}$.

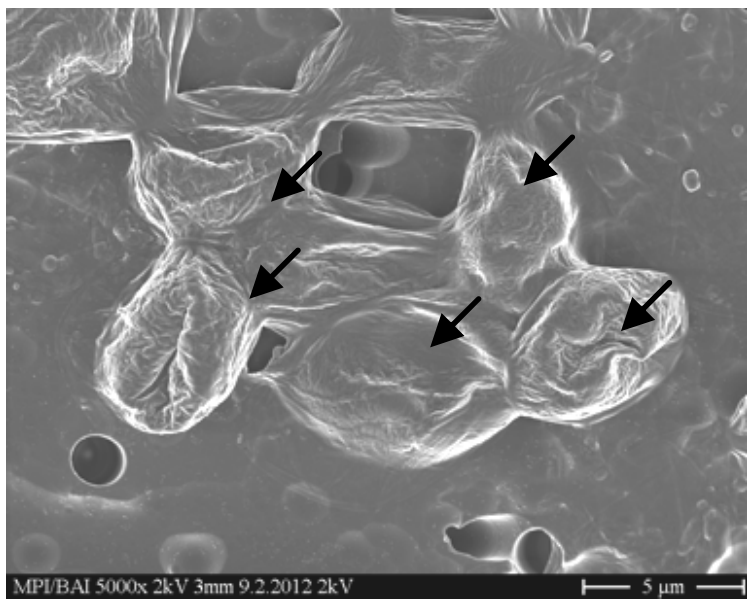

(a)

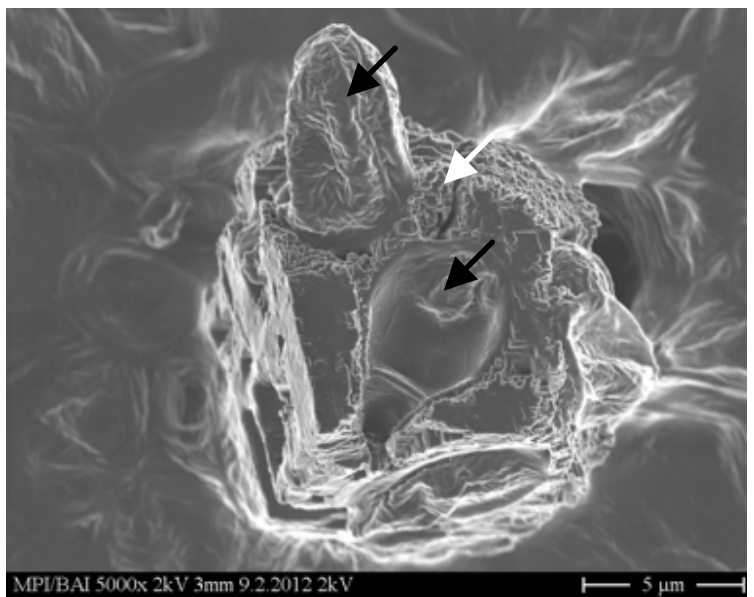

(b)

Figure 2. SEM images. (a) Algae (black arrows) without precipitates at the beginning of the experiment; (b) Crystals (white arrow) with embedded algae were built after $2 \mathrm{~h}$ in the medium without zinc. 


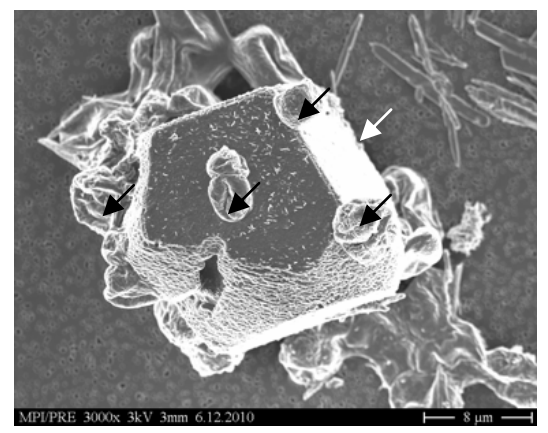

(a)

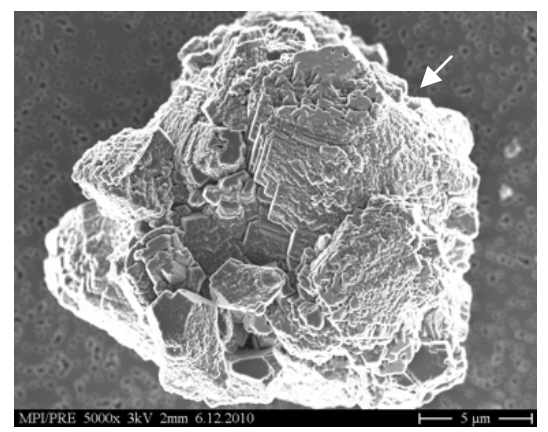

(d)

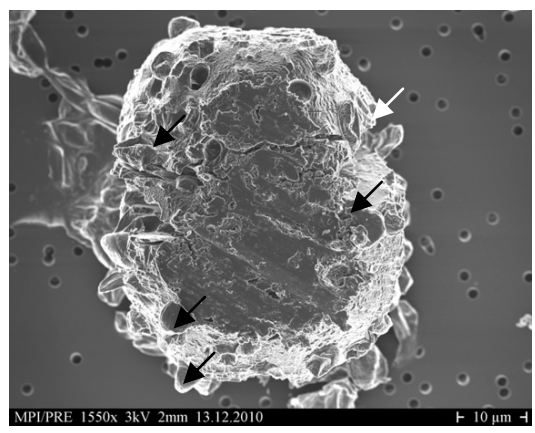

(b)

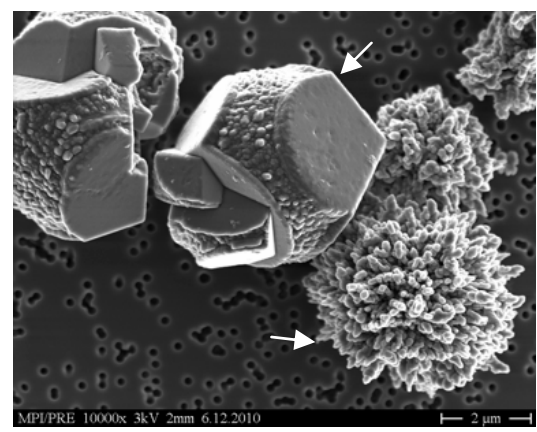

(e)

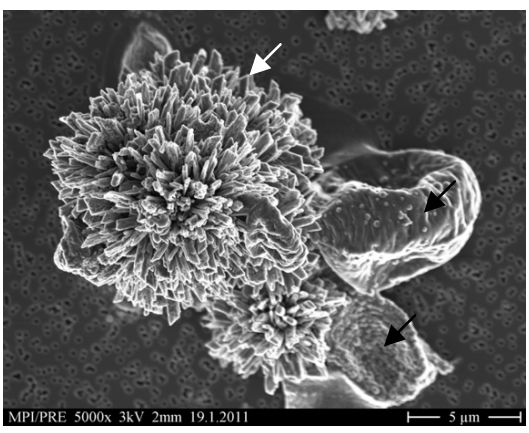

(c)

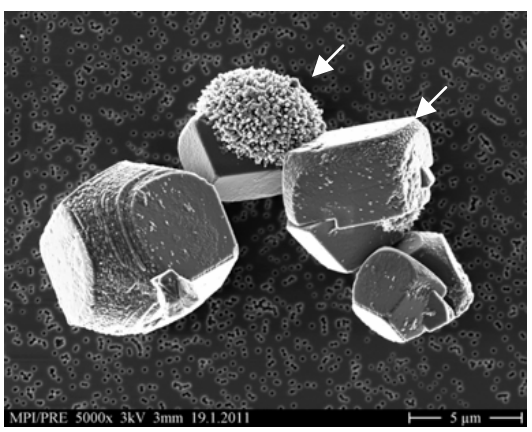

(f)

Figure 3. Crystals after $72 \mathrm{~h}$ of incubation. (a)-(c) Cultures with algae and different amounts of zinc: (a) Without zinc; (b)

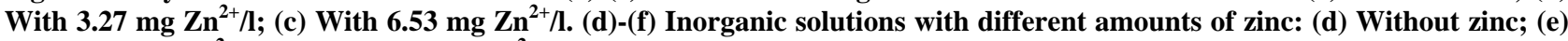
With $3.27 \mathrm{mg} \mathrm{Zn}^{2+} /$; (f) With $6.53 \mathrm{mg} \mathrm{Zn}^{2+} /$. Black arrows-algae, white arrows—crystals.

found in the organic solution with $3.27 \mathrm{mg} \mathrm{Zn}^{2+} / 1$ (Figure 3(b)).

These precipitates appear in the SEM images as big single-crystals, but could also been formed as many smaller crystals and afterwards baked together. In the inorganic solution with zinc, two different crystal types were found (Figures 3(e) and (f)). Due to the crystal morphology we assume that the needle-like crystals refer to aragonite and the rhombohedric to calcite [3].

The crystals found after $72 \mathrm{~h}$ in the experimental solutions were washed and then analyzed regarding their modification by XRD. Representative XRD diagrams are shown in Figures 4 and 5. In the case of solutions without algae cells the dominant (104) reflection of calcite (JCPDS card No. 01-072-1650) can be found in all samples at $29.5^{\circ}$ (3.02 $\AA$ ) (Figure 4). Furthermore, the weaker (012)-, (110)-, (113)-, (202)-, (024)-, (018)-, and (116)-reflection of calcite are present in the sample, which contains no $\mathrm{Zn}^{2+}$ cations within solution. In former studies about precipitation in inorganic solutions, vaterite was found to be the major product in the $\mathrm{pH}$ range between 8.5 and 10 and at $24^{\circ} \mathrm{C} \mathrm{[3].} \mathrm{In} \mathrm{these} \mathrm{experiments,}$ the experimental solution only contained calcium chloride and sodium carbonate. In our studies, a culture medium for algae with a more complex composition was used for all experiments, also for preparing the solutions without algae. This was probably the reason, why calcite was built and not vaterite.

In the inorganic sample which has been formed in medium with $3.27 \mathrm{mg} \mathrm{Zn}^{2+} / 1$ weak intensities (near the detection limit) can also be detected at $26.3^{\circ}, 27.2^{\circ}$, and $46.0^{\circ}$ which can be attributed to the characteristic (111)-, (021)- and (221)-reflections of aragonite (JCPDS card No. 00-003-1067). The reflections of aragonite correspond with SEM observation of a small amount of a second acerous phase (cf. Figure 3(e)). The precipitate of the sample, which has the highest amount of $\mathrm{Zn}^{2+}$ cations within the media, shows only the dominant (104) reflection of calcite. A small amount of aragonite crystals could be observed in this medium by SEM observations (Figure 3(f)), which is below of detection limit of XRD.

The presence of algae cells has a significant influence on the $\mathrm{CaCO}_{3}$ precipitation within media in comparison to media without algal cells, which is demonstrated in Figure 5. In the case of the $\mathrm{Zn}^{2+}$ free media the precipitate is dominated by the reflections of calcite, but small intensities of aragonite are also present (Please note that the strong (104) reflection of calcite at about $29.5^{\circ}$ is cut at about 1600 a.u. within Figure 5(a)). With increasing zinc concentration in the solutions the amount of calcite decreases dramatically. In fact, in the case of media with $6.53 \mathrm{mg} \mathrm{Zn}{ }^{2+} / 1$ no calcite reflections can be determined within the corresponding XRD diagram. Only the reflections of aragonite are present (Figure 5(c)). Thus, the 


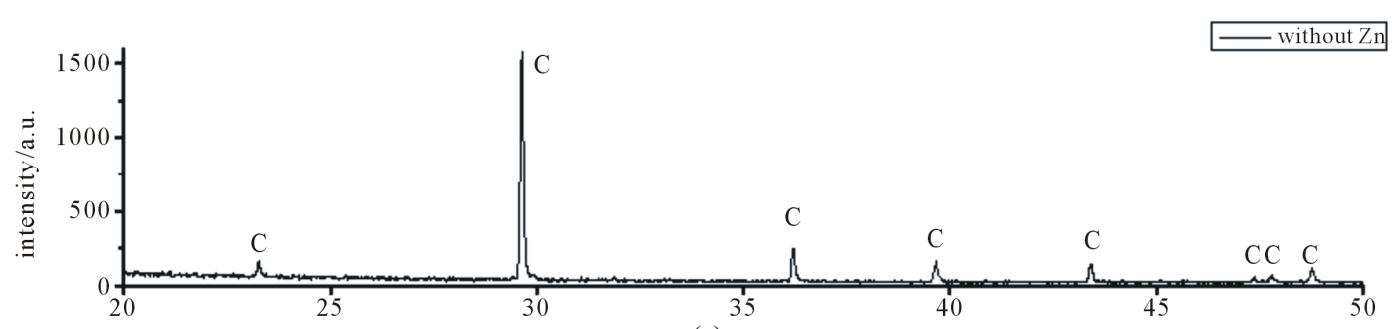

(a)
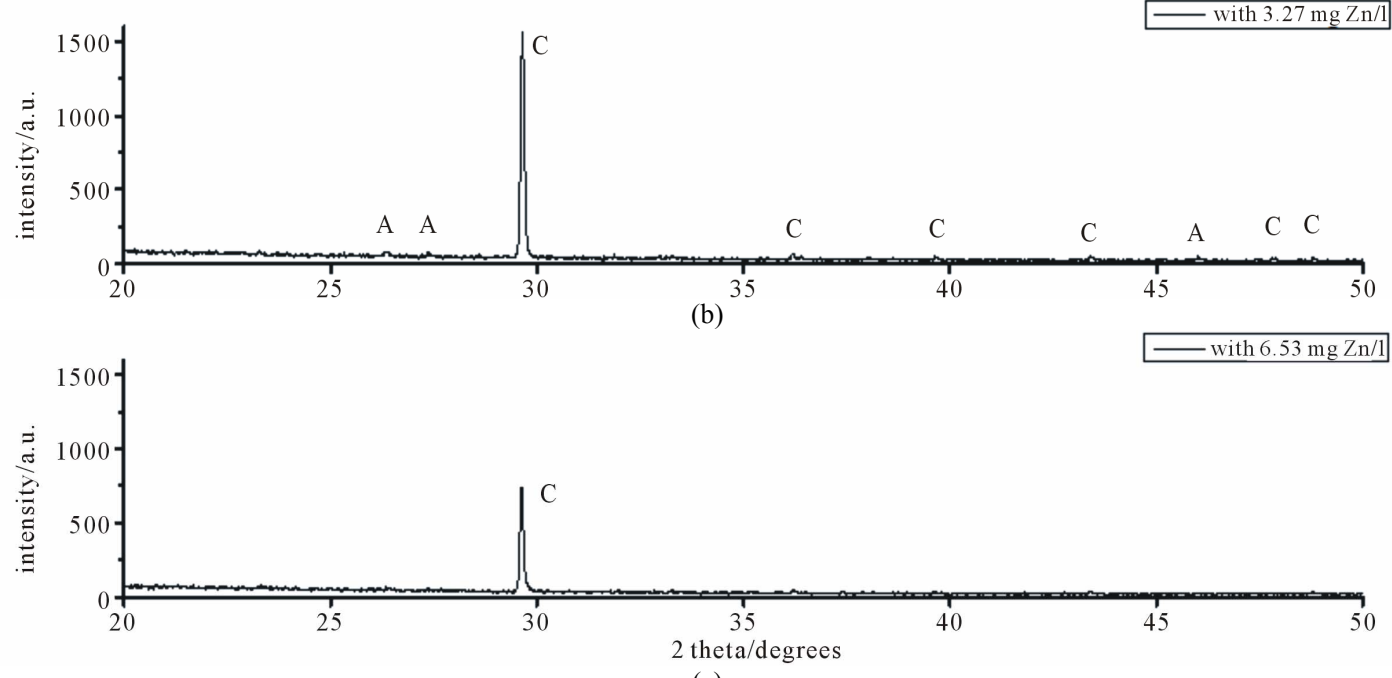

(c)

Figure 4. XRD diagrams of precipitates in absence of algae (72 h of incubation). (a) Without zinc; (b) With $3.27 \mathrm{mg} \mathrm{Zn}^{2+} / \mathrm{l}$; (c) With $6.53 \mathrm{mg} \mathrm{Zn}^{2+} /$.

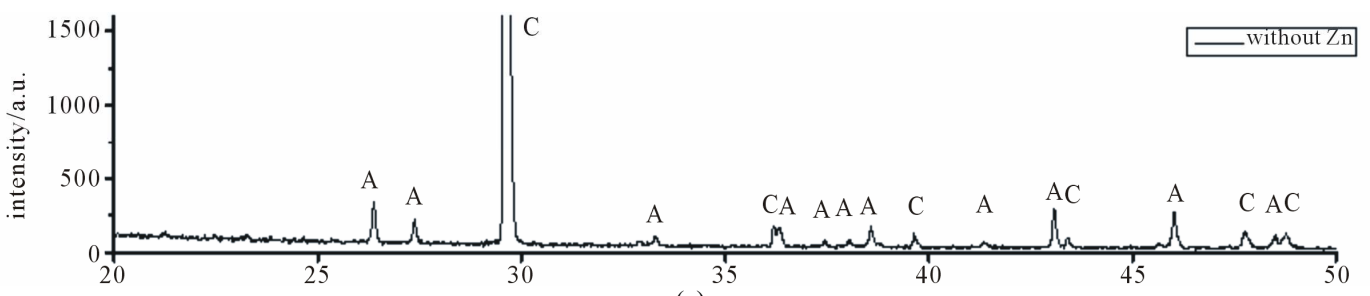

(a)

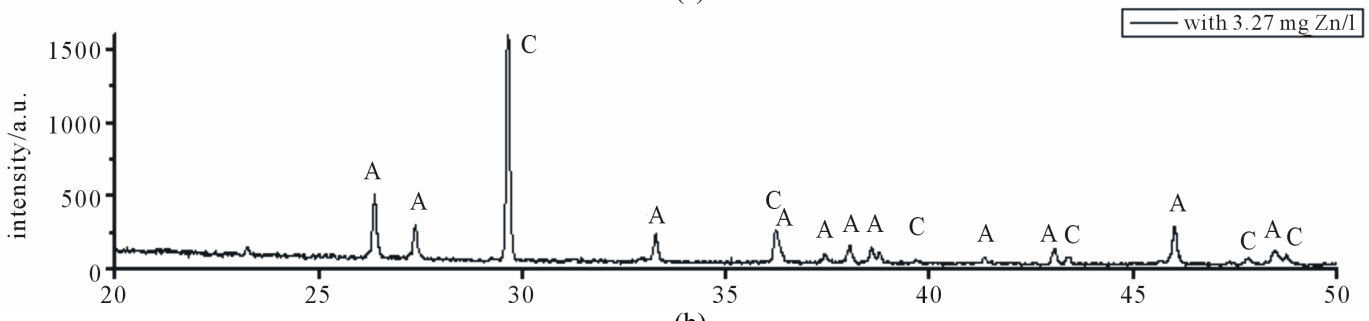

(b)

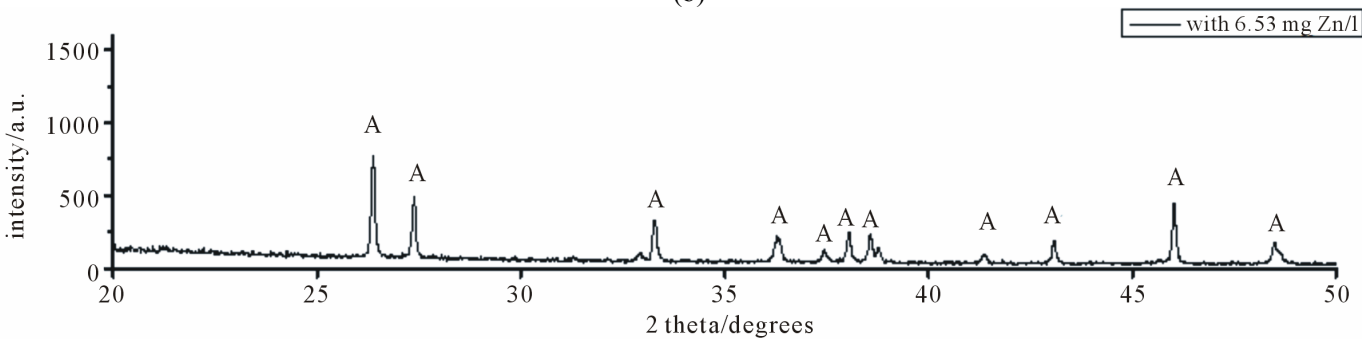

(c)

Figure 5. XRD diagrams of precipitates in presence of algae (72 h of incubation). (a) Without zinc; (b) With $3.27 \mathrm{mg} \mathrm{Zn}^{2+} / \mathrm{l}$; (c) With $6.53 \mathrm{mg} \mathrm{Zn}^{2+} / \mathrm{l}$. 
algae cells advance significantly the formation of aragonite, which is enhanced by the presence of zinc ions in the media.

The algae function obviously as heterogeneous nucleation sites. Since only crystals associated with algae have been found in the solutions, the cell walls are evidently directly involved in nucleation. The binding sites of the cell walls have a great affinity for $\mathrm{Ca}^{2+}$ cations, the bound $\mathrm{Ca}^{2+}$ attract anions like $\mathrm{CO}_{3}^{2-}$ [16]. Our preliminary experiments have shown that Scenedesmus obliquus does not calcify when cultivated in the dark, and the $\mathrm{pH}$ reaches only the maximum of 9 . This was also observed by other authors with different microalga species [17,31]. This shows that the algae do not only act as nucleation sites for $\mathrm{CaCO}_{3}$ precipitation but are actively involved through light-dependent photosynthesis and thus alkalization of the medium. The increase of $\mathrm{pH}$ was measurable in the bulk solution but was probably higher close to the cells. This was also supposed by other authors $[14,17]$. In presence of zinc in the medium the aragonite modification is favored. In this case, obviously the transformation into the thermodynamically stable calcite modification is hindered. A possible mechanism that occurs in micro-environments created by the cells is suggested in Figure 6. A part of the absorbed $\mathrm{Ca}^{2+}$ on the cell wall can be exchanged by $\mathrm{Zn}^{2+}[18]$. The interaction of $\mathrm{Zn}^{2+}$ with the cell wall enables a local enrichment of the ions which are supposed to stabilize the metastable aragonite modification [7] and thus prevents its transformation into thermodynamically stable calcite. Furthermore, $\mathrm{Zn}^{2+}$ ions restrain photosynthesis [28], which is connected with a lower $\mathrm{pH}$ within the micro-environments compared to the algae-containing zinc-free medium. As mentioned above, the formation of aragonite is favoured at lower $\mathrm{pH}$ compared to the one of calcite [3]. Accordingly, only aragonite crystals in the media containing algae and high amounts of zinc are detected. On the contrary, calcite is produced nearly exclusively in the media without algae and high amounts of zinc. Only traces of aragonite are produced, as revealed by SEM observations.

\section{Conclusion}

We compared the precipitates which have been formed in solutions with and without algae and with and without different zinc amounts. We could show that the presence of living microalgae has a great influence on the precipitation of calcium carbonate crystals. Due to photosynthesis, the $\mathrm{pH}$ in the algae-containing organic media increased and $\mathrm{CaCO}_{3}$ crystals are precipitated. In organic

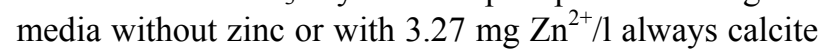
and aragonite are formed. In the organic media with 6.53 $\mathrm{mg} \mathrm{Zn}^{2+} / 1$ aragonite is obtained even exclusively. In contrast, in the inorganic solutions without zinc, pure calcite is precipitated. Both inorganic solutions with zinc show major calcite precipitation and weak aragonite precipitation as revealed by XRD measurements and SEM observations. Thus, the algae cells advance significantly the formation of aragonite, which is further enhanced by the presence of zinc cations in the media. The following effects of algae and zinc in the solution were supposed: first, as the algae accumulate, a "micro-environment" around the clusters is formed, where the $\mathrm{CaCO}_{3}$ is precipitated (Figure 6). When high $\mathrm{Zn}^{2+}$ amounts are present in the solution, photosynthesis is inhibited and the $\mathrm{pH}$ in this "micro-environment" is lower compared to the "micro-environment" around the algae in solution without $\mathrm{Zn}$. The lower $\mathrm{pH}$ prefers the building of aragonite [3]. Second, the algae function as heterogeneous nucleation sites where in the first step $\mathrm{Ca}^{2+}$ and $\mathrm{Zn}^{2+}$ ions are absorbed on the negatively charged cell walls and in the second step anions like $\mathrm{CO}_{3}^{2-}$ are bound (Figure 6). The presence of $\mathrm{Zn}^{2+}$ leads to the precipitation of aragonite [6]. In the "micro-environment" around the cells more $\mathrm{Zn}^{2+}$ ions are present than in the corresponding in-
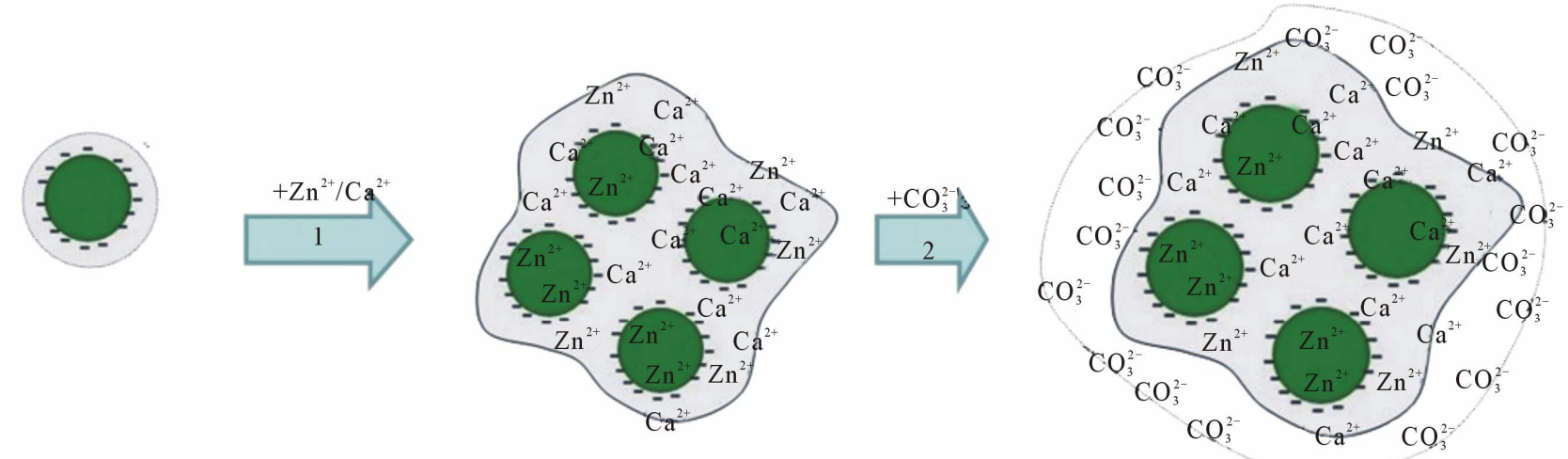

Figure 6. Scheme of possible heterogeneous nucleation of aragonite crystals in presence of algae and zinc. Between several aggregated cells a "micro-environment" is built leading to a local increase of the $\mathrm{pH}$ and $\mathrm{Zn}^{2+}$ ions. 
organic bulk solution, since these ions are attracted from the cell walls and bound on them. $\mathrm{Zn}^{2+}$ ions inhibit the transformation from aragonite to calcite [1]. Hence, aragonite is precipitated in the algae-containing media with high amount of $\mathrm{Zn}$ whereas in the corresponding inorganic solution mainly calcite is found.

\section{Acknowledgements}

We are grateful for financial support provided by the Deutsche Forschungsgemeinschaft (BI 469/15-1) within the scope of the project "Biologische Erzeugung von Oxidkeramiken" (PAK 410). The authors thank M. Dudek and F. Predel (both MPI-IS) for XRD and SEM measurements, respectively. Prof. Dr. P. A. van Aken (MPI-IS) is thanked for providing the SEM.

\section{REFERENCES}

[1] T. Ogino, T. Suzuki and K. Sawada, "The Formation and Transformation Mechanism of Calcium Carbonate in Water," Geochimica et Cosmochimica Acta, Vol. 51, No. 10, 1987, pp. 2757-2767. doi:10.1016/0016-7037(87)90155-4

[2] K. Sawada, "The Mechanisms of Crystallization and Transformation of Calcium Carbonates," Pure \& Applied Chemistry, Vol. 69, No. 5, 1997, pp. 921-928. doi:10.1351/pac199769050921

[3] C. Y. Tai and F.-B. Chen, "Polymorphism of $\mathrm{CaCO}_{3}$ Precipitated in a Constant-Composition Environment," AIChE Journal, Vol. 44, No. 8, 1998, pp. 1790-1978. doi:10.1002/aic.690440810

[4] J. Chen and L. Xiang, "Controllable Synthesis of Calcium Carbonate Polymorphs at Different Temperatures," Powder Technology, Vol. 189, No. 1, 2009, pp. 64-69.

[5] R. D. Shannon, "Revised Effective Ionic Radii and Systematic Studies of Interatomic Distances in Halides and Chalcogenides," Acta Crystallographica, Vol. A32, No. 5, 1976, pp. 751-767.

[6] H. Roques and A. Girou, "Kinetics of the Formation Conditions of Carbonate Tartars," Water Research, Vol. 5, No. 11, 1974, pp. 907-920. doi:10.1016/0043-1354(74)90105-5

[7] Y. Kitano, N. Kanamori and S. Yoshioka, "Adsorption of Zinc and Copper Ions on Calcite and Aragonite and Its Influence on the Transformation of Aragonite to Calcite," Geochemical Journal, Vol. 10, No. 4, 1976, pp. 175-179. doi:10.2343/geochemj.10.175

[8] J. M. Zachara, J. A. Kittrick and J. B. Harsh, "The Mechanism of $\mathrm{Zn}^{2+}$ Adsorption on Calcite," Geochimica et Cosmochimica Acta, Vol. 52, No. 9, 1988, pp. 22812291. doi:10.1016/0016-7037(88)90130-5

[9] F. C. Meldrum, "Calcium Carbonate in Biomineralisation and Biometric Chemistry," International Materials Reviews, Vol. 48, No. 3, 2003, pp. 187-224. doi: $10.1179 / 095066003225005836$

[10] D. Ren, Q. Feng and X. Bourrat, "Effects of Additives and Templates on Calcium Carbonate Mineralization in Vitro," Micron, Vol. 42, No. 3, 2011, pp. 228-245. doi:10.1016/j.micron.2010.09.005

[11] W. Hou and Q. Feng, "Morphology and Formation Mechanism of Vaterite Particles Grown in Glycine-Containing Aqueous Solutions," Materials Science and Engineering, Vol. C26, No. 4, 2006, pp. 644-647. doi:10.1016/j.msec.2005.09.098

[12] F. Manoli and E. Dalas, "Calcium Carbonate Crystallization in the Presence of Glutamic Acid," Journal of Crystal Growth, Vol. 222, No. 1, 2001, pp. 293-297. doi:10.1016/S0022-0248(00)00893-9

[13] H. Matahwa, V. Ramiah and R. D. Sanderson, "Calcium Carbonate Crystallization in the Presence of Modified Polysaccharides and Linear Polymeric Additives," Journal of Crystal Growth, Vol. 310, No. 21, 2008, pp. 45614569. doi:10.1016/j.jcrysgro.2008.07.089

[14] M. Dittrich, P. Kurz and B. Wehrli, "The Role of Autotrophic Picocyanobacteria in Calcite Precipitation in an Oligotrophic Lake," Geomicrobiology Journal, Vol. 21, No. 1, 2004, pp. 45-53. doi:10.1080/01490450490253455

[15] M. Dittrich and M. Obst, "Are Picoplankton Responsible for Calcite Precipitation in Lakes?" Ambio, Vol. 33, No. 8, 2004, pp. 559-564.

[16] M. A. Borowitzka, "Calcification in Algae: Mechanisms and the Role of Metabolism," CRC Critical Reviews in Plant Sciences, Vol. 6, No. 1, 1987, pp. 1-45. doi:10.1080/07352688709382246

[17] C. R. Heath, B. C. S. Leadbeater and M. E. Callow, "Effect of Inhibitors on Calcium Carbonate Deposition Mediated by Freshwater Algae," Journal of Applied Phycology, Vol. 7, No. 4, 1995, pp. 367-380. doi:10.1007/BF00003794

[18] R. H. Crist, J. R. Martin, D. Carr, J. R. Watson and H. J. Clarke, "Interaction of Metals and Protons with Algae. 4. Ion Exchange vs Adsorption Models and a Reassessment of Scatchard Plots; Ion-Exchange Rates and Equilibria Compared with Calcium Alginate," Environmental Science \& Technology, Vol. 28, No. 11, 1994, pp. 18591866. doi:10.1021/es00060a016

[19] E. Kiefer, L. Sigg and P. Schosseler, "Chemical and Spectroscopic Characterization of Algae Surfaces," Environmental Science \& Technology, Vol. 31, No. 3, 1997, pp. 759-764. doi:10.1021/es960415d

[20] C.-P. Huang, C.-P. Huang and A. L. Morehart, "The Removal of $\mathrm{Cu}$ (II) Form Dilute Aqueous Solutions by Saccharomyces cerevisiae," Water Research, Vol. 24, No. 4, 1990, pp. 433-439. doi:10.1016/0043-1354(90)90225-U

[21] B. Volesky and Z. R. Holan, "Biosorption of Heavy Metals," Biotechnology Progress, Vol. 11, No. 3, 1995, pp. 235-250. doi:10.1021/bp00033a001

[22] P. Ahuja, R. Gupta and R. K. Saxena, " $\mathrm{Zn}^{2+}$ Biosorption by Oscillatoria anguistissima," Process Biochemistry, Vol. 34, No. 1, 1999, pp. 77-85. doi:10.1016/S0032-9592(98)00072-7

[23] F. A. Abu Al-Rub, M. H. El-Naas, F. Benyahia and I. Ashour, "Biosorption of Nickel on Blank Alginate Beads, Free and Immobilized Algal Cells," Process Biochemistry, 
Vol. 39, No. 11, 2004, pp. 1767-1773. doi:10.1016/j.procbio.2003.08.002

[24] K. Chojnacka, A. Chojnacki and H. Górecka, "Biosorption of $\mathrm{Cr}^{3+}, \mathrm{Cd}^{2+}$ and $\mathrm{Cu}^{2+}$ Ions by Blue-Green Algae Spirulina sp.: Kinetics, Equilibrium and the Mechanism of the Process," Chemosphere, Vol. 59, No. 1, 2005, pp. 75-84. doi:10.1016/j.chemosphere.2004.10.005

[25] R. Gong, Y. Ding, H. Liu, Q. Chen and Z. Liu, "Lead Biosorption and Desorption by Intact and Pretreated Spirulina Maxima Biomass," Chemosphere, Vol. 58, No. 1, 2005, pp. 125-130.

doi:10.1016/j.chemosphere.2004.08.055

[26] L. Deng, Y. Su, H. Su, X. Wang and X. Zhu, "Sorption and Desorption of Lead (II) from Wastewater by Green Algae Cladophora fascicularis," Journal of Hazardous Materials, Vol. 143, No. 1-2, 2007, pp. 220-225. doi:10.1016/j.jhazmat.2006.09.009

[27] C. M. Monteiro, A. P. G. C. Marques, P. M. L. Castro and F. X. Malcata, "Characterization of Desmodesmus pleiomorphus Isolated from a Heavy Metal-Comtamined Site: Biosorption of Zinc," Biodegradation, Vol. 20, No. 5, 2009, pp. 629-641. doi:10.1007/s10532-009-9250-6
[28] B. N. Tripathi and J. P. Gaur, "Physilogical Behavior of Scenedesmus sp. during Exposure to Elevated Levels of $\mathrm{Cu}$ and $\mathrm{Zn}$ and after Withdrawal of Metal Stress," Protoplasma, Vol. 229, No. 1, 2006, pp. 1-9. doi:10.1007/s00709-006-0196-9

[29] Y. P. Ting, F. Lawson and I. G. Prince, "Uptake of Cadmium and Zinc by the Alga Chlorella vulgaris: Part 1. Individual Ion Species," Biotechnology and Bioengineering, Vol. 34, No. 7, 1989, pp. 990-999. doi:10.1002/bit.260340713

[30] G. Santomauro, V. Srot, B. Bussmann, P. A. van Aken, F. Brümmer, H. Strunk and J. Bill, "Biomineralization of Zinc-Phosphate-Based Nano Needles by Living Microalgae," Journal of Biomaterials and Nanobiotechnology, Vol. 3, No. 3, 2012, pp. 362-370. doi:10.4236/jbnb.2012.33034

[31] A. M. Hartley, W. A. House, M. E. Callow and B. S. C. Leadbeater, "The Role of a Green Alga in the Precipitation of Calcite and the Coprecipitation of Phosphate in Freshwater," Internationale Revue gesamten Hydrobiologie, Vol. 80, No. 3, 1995, pp. 385-401. doi:10.1002/iroh.19950800302 